DOI: https://doi.org/10.47405/mjssh.v5i10.509

\begin{tabular}{|c|c|}
\hline 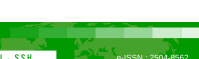 & Malaysian Journal of Social Sciences and Humanities (MJSSH) \\
\hline Malaysian Journal of & Volume 5, Issue 10, October 2020 \\
\hline $\begin{array}{l}\text { Humantives } \\
\text { (MJ-sSH) }\end{array}$ & e-ISSN : 2504-8562 \\
\hline 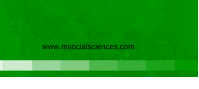 & $\begin{array}{l}\text { Journal home page: } \\
\text { www.msocialsciences.com }\end{array}$ \\
\hline
\end{tabular}

\title{
Kemampuan ICT “WhatsApp” Sebagai Medium Komunikasi Berkesan
}

\author{
Malini Binti Kamlin', Tan Choon Keong1 \\ 1Universiti Malaysia Sabah (UMS) \\ Correspondence: Malini Binti Kamlin (malini.kamlin0121@gmail.com)
}

\begin{abstract}
Abstrak
'WhatsApp' merupakan medium penghantaran teks dan bahan multimedia menerusi telefon pintar. Kajian ini menggunakan 'WhatsApp' sebagai medium komunikasi antara pelajar dan guru. Kemampuan ICT yang diperolehi menerusi medium komunikasi 'WhatsApp' mampu menyediakan peluang pembelajaran yang efektif dari aspek melibatkan pedagogi, sosial dan teknikal. Sampel kajian terdiri daripada 150 pelajar di salah sebuah sekolah menengah di Kota Kinabalu, Sabah menggunakan kaedah kuantitatif jenis kajian tinjauan. Dapatan kajian menunjukkan pelajar mempunyai persepsi yang positif terhadap penggunaan 'WhatsApp' dalam proses pembelajaran. Pelajar turut menyatakan 'WhatsApp' sebagai medium yang memudahkan proses komunikasi, perkongsian, perbincangan dalam talian dan merupakan salah satu aplikasi yang mudah digunakan. Kesimpulannya, kemampuan ICT dari aspek pedagogi, sosial dan teknikal yang diperolehi daripada komunikasi menerusi 'WhatsApp' menjadikannya satu medium yang efektif dan berkesan diaplikasikan bagi tujuan pengajaran dan pembelajaran.
\end{abstract}

Kata kunci: WhatsApp', kemampuan ICT, komunikasi

\section{ICT Affordances of WhatsApp as an Effective Communication Medium}

\begin{abstract}
WhatsApp is a medium used to send messages such as text and multimedia via smartphone. This study used WhatsApp as a medium of communication among students and teachers. The ICT affordances found through the use of WhatsApp as a medium of communication enables the chances of effective learning from the pedagogical, social and technical aspect. The research sample of this study consists of 150 students from a secondary school in Kota Kinabalu, Sabah using a survey research, a type of quantitative method used for this study. The study found students have positive perception about WhatsApp usage in the learning process. Students also stated that WhatsApp is a medium that ease the communication, sharing and online discussion process as well as one of the easy to use applications. In conclusion, the ICT affordances in pedagogy, social and technical aspect obtained through Whatsapp communication enables it to be applied as an effective medium for teaching and learning.
\end{abstract}

Keywords: WhatsApp, ICT affordances, communication 


\section{Pengenalan}

'WhatsApp' adalah merupakan aplikasi rangkaian sosial yang popular dan sering digunakan pada masa kini untuk tujuan komunikasi (Abdul Fattah, 2015). Aplikasi ini merupakan salah satu daripada aplikasi yang terdapat pada telefon pintar (Bouhnik \& Deshen, 2014). Terdapat beberapa fungsi yang terdapat dalam 'WhatsApp' melibatkan penghataran teks, imej, video, audio, dan pelbagai format fail seperti pdf., doc. dan sebagainya. Dengan menggunakan 'WhatsApp', komunikasi boleh berlaku dengan kehadiran jaringan internet disertai dengan kos yang murah (Kumar \& Sharma, 2017). Perkembangan aplikasi teknologi telefon pintar dalam pengajaran dan pembelajaran menerusi pembelajaran peranti mudah alih seperti telefon pintar telah menjadikan 'WhatsApp' sebagai salah satu medium komunikasi pilihan.

Masalah komunikasi yang terbatas sewaktu di dalam kelas dengan kekangan waktu masa pembelajaran yang terhad menjadikan 'WhatsApp' sebagai alat penghubung antara pelajar dan guru sewaktu berada di luar sekolah. Sewaktu berada di dalam kelas komunikasi antara guru dan pelajar terhad disebabkan batasan masa dan bilangan pelajar yang ramai. Oleh itu, sebagai alternatif, medium komunikasi menerusi 'WhatsApp' boleh digunakan. Sebarang masalah ataupun isu yang timbul boleh diselesaikan menerusi perbincangan, kolaborasi dan perkongsian maklumat antara guru dan pelajar, dan antara pelajar dan rakan.

Kepentingan kajian ini dilihat daripada aplikasi teknologi 'WhatsApp' untuk mengatasi had komunikasi antara pelajar dan guru semasa berada di sekolah. Sewaktu berada di luar sekolah, dengan menggunakan 'WhatsApp', pelajar dapat berhubung dengan guru dan rakan-rakan jika sekiranya mereka menghadapi sebarang masalah atau pertanyaan. Disamping itu, proses kolaborasi menerusi perbincangan dapat dibuat bersama guru ataupun rakan menerusi kumpulan yang dibuat dalam medium 'WhatsApp'. Selain itu, menerusi 'WhatsApp' perkongsian bahan dan idea dapat dilakukan dengan ahli kumpulan. Sumber informasi sebegini penting bagi membantu pelajar untuk mengatasi sebarang isu dan permasaalahan dan dapat mengembangkan pengetahuan sedia ada.

\section{Objektif dan Persoalan Kajian}

Objektif kajian ini adalah untuk mengenalpasti persepsi pelajar terhadap penggunaan 'WhatsApps' sebagai medium komunikasi berdasarkan kepada Model Kemampuan ICT

Persoalan kajian: Apakah persepsi pelajar terhadap penggunaan 'WhatsApp' sebagai medium komunikasi berdasarkan kepada Model Kemampuan ICT?

\section{Sorotan Literatur}

'WhatsApp' adalah medium komunikasi sosial yang paling banyak digunakan di Malaysia (SKMM, 2018). Terdapat banyak kajian lepas yang menunjukkan penggunaan 'WhatsApp' dapat memberikan kesan yang efektif terhadap proses pengajaran dan pembelajaran. Menurut (Bouhnik \& Deshen, 2014), penggunaan 'WhatsApp' dalam proses pembelajaran memudahkan pelajar bertukar-tukar maklumat dan informasi, maklum balas diperolehi secara pantas dan dapat membina pengetahuan baru hasil daripada kolaborasi dengan rakan-rakan kumpulan 'WhatsApp'. Pertukaran idea membolehkan pelajar membuat analisis dan akhirnya pengetahuan baru akan terhasil. Menerusi kajian lepas yang dijalankan oleh Yu et al. (2010), 70\% pelajar mengatakan pembelajaran menerusi komuniti dalam talian seperti kumpulan 'WhatsApp', kumpulan 'Twitter' dapat memberikan medium pembelajaran yang lebih baik kepada pelajar. Justeru, menerusi manfaat dan kebaikan yang diperolehi daripada penggunaan 'WhatsApp', secara tidak langsung memberikan kesan yang positif dalam aspek pencapaian pembelajaran.

Pembelajaran menerusi interaksi dalam komuniti sosial seperti perbincangan secara dalam talian menggunakan medium 'Mobile Learning' secara tidak langsung akan dapat memperbaiki perhubungan 
sosial dan keyakinan diri (Awada \& Wang 2016). Penggunaan 'WhatsApp' dalam pengajaran dan pembelajaran mampu memberikan peluang kepada pelajar untuk berinteraksi dengan kandungan pembelajaran, guru dan juga rakan-rakan di luar kelas (Baguma \& Bagarukayo, Namubiru, Brown \& Mayisela, 2019). Menerusi kajian oleh Jisha \& Jebakumar (2014) dan Sayan (2016), 'WhatsApp' banyak digunakan untuk tujuan komunikasi dengan rakan menerusi perkongsian imej, audio dan video. Selain itu, 'WhatsApp' juga digunakan untuk berkongsi bahan menerusi pautan laman web, nota, tugasan, dan bahan kursus dan berfungsi sebagai alat untuk meningkatkan komunikasi antara guru dan pelajar (Mazana, 2018). Elemen multimedia yang diaplikasikan dalam pembelajaran menggunakan teknologi dapat menarik minat pelajar dan meningkatkan pengelibatan dalam proses pembelajaran. Pelajar menyatakan pembelajaran berlaku tanpa disedari menerusi mesej dan imej yang di hantar menerusi 'WhatsApp' dan ia dianggap sebagai salah satu medium pembelajaran yang efektif (Cetinkaya, 2017).

Selain digunakan sebagai satu medium untuk mencapai matlamat pembelajaran, 'WhatsApp' merupakan medium bagi membina hubungan interpersonal antara pelajar (Shahid, 2018). 'WhatsApp' diterima sebagai alat yang dapat memperbaiki dan menguatkan interaksi antara pelajar dan merapatkan jurang komunikasi antara pelajar dan guru (Robles et al. 2019). Justeru, penggunaan 'WhatsApp' dalam proses pengajaran dan pembelajaran dianggap sebagai satu alat yang dapat membantu bagi menyelesaikan masalah pembelajaran, meningkatkan produktiviti dan efektiviti disamping dapat mengeratkan hubungan antara guru dan pelajar.

\section{Model Kemampuan ICT}

Model kemampuan ICT atau 'ICT Affordances Model' digunakan untuk menguji persepsi murid terhadap penggunaan 'WhatsApp' dalam proses pembelajaran. Model ini diperkenalkan oleh Wang et al. (2012) yang dikaitkan dengan pengalaman pelajar dalam aspek pedagogi, sosial dan teknikal.

\section{Metod Kajian}

Kajian ini menggunakan kaedah kuantitatif jenis kajian tinjauan untuk mendapatkan maklumat tentang kemampuan ICT yang diperolehi daripada penggunaan 'WhatsApp' sebagai medium komunikasi menerusi aspek pedagogi, sosial dan teknikal. Seramai $(n=150)$ orang pelajar sekolah menengah yang terdiri daripada 66 lelaki dan 84 perempuan telah menjadi sampel kajian menerusi pemilihan sampel secara rawak mudah. Kajian ini menggunakan instrumen persepsi pelajar terhadap penggunaan 'WhatsApp' sebagai medium komunikasi antara guru dan rakan yang diadaptasi daripada instrumen persepsi terhadap penggunaan 'Facebook group' sebagai medium pembelajaran oleh Wang et al. (2012).

\section{Hasil Kajian}

Hasil dapatan kajian telah dianalisis menggunakan perisian SPSS 23 dan dihuraikan berdasarkan kepada data yang diperolehi menggunakan analisis statistik deskriptif melibatkan min dan sisihan piawai berdasarkan kepada kemampuan ICT aspek pedagogi, aspek sosial dan aspek teknikal (Jadual $1)$.

\section{Pedagogi}

Pedagogi merujuk kepada kemampuan 'WhatsApp' dalam memberikan kemudahan kepada proses pembelajaran. Data menunjukkan pelajar bersetuju mengatakan penggunaan 'WhatsApp' membolehkan mereka berkongsi sumber bahan pembelajaran dalam kumpulan 'Whatsapp' daripada pelbagai format seperti 'power point' dan format dokumen $(\mathrm{M}=3.60, \mathrm{SP}=1.14)$. Perkongsian ini dapat memberikan maklumat dan pengetahuan baru. Menerusi 'Whatsapp', pelajar dapat membuat perbincangan dalam 
DOI: https://doi.org/10.47405/mjssh.v5i10.509

talian bersama rakan $(\mathrm{M}=3.52, \mathrm{SP}=1.16)$. Dari aspek pedagogi, penggunaan 'WhatsApp' dilihat dapat membantu pelajar untuk mengembangkan pengetahuan menerusi perkongsian dan perbincangan.

\section{Sosial}

Pelajar merasakan terdapatnya hubungan yang erat terjalin menerusi penggunaan 'WhatsApp' dalam sesuatu jaringan sosial dan ini ditunjukkan menerusi nilai tahap min yang tertinggi $(\mathrm{M}=3.78, \mathrm{SP}=$ 1.09). Pelajar juga merasakan 'WhatsApp' menyediakan persekitaran pembelajaran yang mesra pengguna bagi interaksi antara sesama rakan dan guru. $(\mathrm{M}=3.65, \mathrm{SP}=1.27)$. Pelajar merasa selesa untuk berkomunikasi menerusi 'WhatsApp' $(\mathrm{M}=3.56$, $\mathrm{SP}=1.28)$, dan bersetuju menyatakan 'Whatsapp' adalah merupakan medium yang dirasakan selamat untuk berkongsi sebarang idea dan sumber maklumat serta bahan pembelajaran $(\mathrm{M}=3.56, \mathrm{SP}=1.29)$. Kesimpulannya, 'WhatsApp' adalah merupakan medium yang dirasakan fleksibel serta dapat memberikan keselesaan kepada pengguna semasa dalam proses komunikasi dan perkongsian. Implikasinya, penerimaan 'WhastApp' dari aspek sosial dapat diaplikasikan dalam proses pembelajaran terutamanya dalam proses kolaborasi dan perbincangan.

\section{Teknikal}

Pelajar tidak menghadapi sebarang masalah teknikal semasa mengaplikasikan proses pembelajaran menerusi 'WhatsApp' $(\mathrm{M}=3.78, \mathrm{SP}=1.21)$. Ini menjunjukkan, 'WhatsApp' adalah merupakan salah satu medium komunikasi yang mudah digunakan. Selain itu, pelajar merasa mudah untuk muat turun dan muat naik sebarang dokumen menerusi 'WhatsApp' $(\mathrm{M}=4.08, \mathrm{SP}=1.12)$. Proses muat turun dan muat naik yang mudah membolehkan proses perkongsian sumber informasi, bahan dan maklumat dapat dijalankan dengan mudah dan pantas. Justeru, perkongsian bahan pembelajaran akan dapat membantu pelajar untuk mendapatkan sumber maklumat dengan mudah.

Jadual 1: Persepsi terhadap 'WhatsApp’ sebagai medium Komunikasi

\begin{tabular}{ll}
\hline Pelajar $(\mathrm{n}-150)$ \\
Min SP
\end{tabular}

Kemampuan Pedagogi

1. Saya boleh berkongsi bahan pembelajaran dalam sebarang format seperti PPT atau DOC dalam kumpulan 'WhatsApp'

$3.60 \quad 1.14$

2. 'WhatsApp' membolehkan saya dan rakan-rakan untuk membuat perbincangan secara dalam talian

Kemampuan Sosial

3. Kumpulan 'WhatsApp' menyediakan persekitaran yang selamat untuk perkongsian idea dan bahan

4. Kumpulan 'WhatsApp' menyediakan persekitaran yang mesra untuk proses interaksi sosial dengan rakan dan guru

5. Kumpulan 'WhatsApp' membolehkan saya dan rakan-rakan untuk berkomunikasi mengikut keselesaan

6. Saya merasakan perhubungan yang erat wujud sesama ahli dalam kumpulan 'WhatsApp'

Kemampuan Teknikal

7. Saya tidak menghadapi masalah teknikal semasa menggunakan 'WhatsApp'

8. Mudah untuk saya muat naik dan muat turun bahan dalam format seperti (PPT, DOC, PDF, laman web) 


\section{Perbincangan}

Hasil daripada data yang diperolehi, pelajar mempunyai persepsi yang positif terhadap penggunaan 'WhatsApp' dalam proses pembelajaran yang ditunjukkan daripada nilai tahap min yang tinggi. Dari aspek pedagogi, 'WhatsApp' dapat memudahkan proses pembelajaran menerusi perkongsian sesama ahli yang terdapat dapat kumpulan dan perkongsian ini dapat membantu mengatasi sebarang masalah yang di hadapi oleh ahli yang lain. Bersamaan dengan kajian yang dijalankan oleh Jisha \& Jebakumar (2014), Sayan (2016) dan Mazana (2018), antara tujuan komunikasi menerusi 'WhatsApp' adalah melibatkan perkongsian elemen multimedia seperti video, audio dan gambar. Dari aspek sosial, menerusi 'WhatsApp' guru dan pelajar dapat berkomunikasi secara berterusan menerusi medium yang selesa dan fleksibel. Apek teknikal memaparkan 'WhatsApp' sebagai satu medium yang mudah dan efisein untuk digunakan sebagai medium komunikasi. Disokong oleh kajian oleh (Baguma \& Bagarukayo, Namubiru, Brown \& Mayisela, 2019) yang menyatakan penggunaan 'WhatsApp' dapat memberikan medium pembelajaran yang lebih baik. Oleh itu, 'WhatsApp' dilihat sebagai medium yang wajar digunakan bagi membantu proses komunikasi antara guru dan pelajar dan komunikasi dengan rakan sebaya. Manfaat yang diperolehi menerusi kemampuan ICT dapat membantu guru dan pelajar untuk memperbaiki proses interaksi dan komunikasi.

\section{Kesimpulan}

Daripada dapatan kajian, dapatlah disimpulkan bahawa, 'WhatsApp' adalah merupakan medium komunikasi yang efektif menerusi aspek pedagogi, sosial dan teknikal yang diperolehi daripada kemampuan ICT yang terdapat pada telefon pintar sebagai alat teknologi komunikasi. Elemen mudah alih yang terdapat pada telefon pintar menjadikan aplikasi 'WhatsApp' menyokong komunikasi tanpa mengira masa dan tempat. Oleh itu, dalam bidang pengajaran dan pembelajaran, komunikasi menerusi 'WhatsApp' dapat merapatkan jurang komunikasi antara guru dan pelajar sewaktu berada di sekolah dan pada masa yang sama komunikasi dapat diteruskan sewaktu berada di luar sekolah. Justeru, proses pengajaran dan pembelajaran berterusan menggunakan medium 'WhatsApp' dianggap relevan dengan kehadiran teknologi mudah alih pada masa kini.

\section{Rujukan}

Abdul Fattah, S. F. E. S. (2015). The Effectiveness of Using WhatsApp Messenger as One of Mobile Learning Techniques to Develop Students' Writing Skills. Journal of Education and Practice, 6(32). 115-127.

Amry, A. B. (2014). The Impact of WhatsApp Mobile Social Learning on the Acheivement and Attitudes of Female Students Compared with Face to Face Learning in the Classroom. European Scientific Journal,10(22), 116-136.

Awada, G. \& Wang, S. (2016). Effect of WhatsApp on Critique Writing Proficiency and Perceptions Toward Learning, Cogent Education, 3:1, DOI: 10.1080/2331186X.2016.1264173.

Baguma, R. \& Bagarukayo, E., Namubiru, P., Brown, C. \& Mayisela, T. (2019). Using WhatsApp in Teaching to Develop Higher Order Thinking Skills-a Literature Review Using the Activity Theory Lens. International Journal of Education and Development using Information and Communication Technology (IJEDICT), 15(2), 98-116.

Bouhnik, D., \& Deshen, M. (2014). WhatsApp Goes to School: Mobile Instant Messaging between Teachers and Students. Journal of Information Technology Education: Research, 13, 217-231.

Cetinkaya, L. (2017). The Impact of Whatsapp Use on Success in Education Process. The International Review of Research in Open and Distributed Learning.

Hanisi, Ajid \& Risdiany, Reni \& Utami, Yunita \& Sulisworo, Dwi. (2018). The use of WhatsApp in collaborative learning to improve English teaching and learning process. International Journal of Research Studies in Educational Technology, 7(1), 30-36.

Jisha K. \& , Dr. Jebakumar (2014). Whatsapp: A Trend Setter in Mobile Communication among Chennai Youth. IOSR Journal Of Humanities And Social Science (IOSR-JHSS), 19(9), 1-6. 
Gon, S. Rawekar, A. (2017). Effectivity of E-Learning through Whatsapp as a Teaching Learning Tool. MVP Journal of Medical Sciences, 4(1), 19-25.

Kufre, A., \& Abe, E. (2017). Effectiveness of Whatsapp as a Collaborative Tool for Learning among Undergraduate Students in University of Uyo, Akwa Ibom state. International Journal of Advanced Education and Research, 2(5), 43-46.

Kumar, N. \& Sharma, S. (2017). Survey Analysis on the usage and Impact of Whatsapp Messenger. Global Journal of Enterprise Information System, 8(3),

La Hanisi, A., Risdiany, R., Dwi Utami, Y., \& Sulisworo, D. (2018). The Use of WhatsApp in Collaborative Learning to Improve English Teaching and Learning Process. International Journal of Research Studies in Educational Technology, 7(1), 29-35.

Mazana, M. Y. (2018). Social Media in the Classroom: WhatsApp a New Communication Tool for Enhanced Class Interaction. Business Education Journal, 2(1), 1-8.

Robles, Guerrero, Llinás \& Montero. (2019). Online teacher- students interactions using WhatsApp in a law course. Journal of Information Technology Education: Research, 18, 231-252. https://doi.org/10.28945/4321.

Robinson, L., Behi, O., Corcoran, A., Cowley, V., Cullinane, J., Martin, I., \& Tomkinson, D. (2015). Evaluation of Whatsapp for Promoting Social Presence in a First Year Undergraduate Radiography Problem-Based Learning Group. Journal of Medical Imaging and Radiation Sciences, 46, 280-286.

Sayan, H. (2016). Affecting HIgher Students Learning Activity by Using WhatsApp. European Journal of Research and Reflection in Educational Sciences, 4(3), 88-93.

Shahid, S. (2018). Content Analysis of Whatsapp Conversations: An Analytical Study to Evaluate the Effectiveness of Whatsapp Application in Karachi. International Journal of Media, Journalism and Mass Communications (IJMJMC), 4(1), 14-26.

Suruhanjaya Komunikasi dan Multimedia Malaysia (2018). Internet Users Survey 2018.

Wang,Q., Woo, H. L., Quek, C. L., Yang, Y.\& Liu, M. (2012). Using the Facebook group as a learning management system:An exploratory study. British Journal of Educational Technology, 43(3), 428-438. URL: doi:10.1111/j.1467-8535.2011.01195.x. 